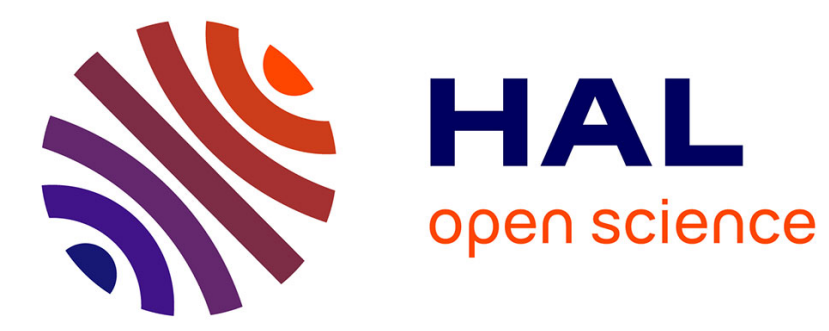

\title{
The first bilayer ferroelectric liquid crystal
}

\author{
H.R. Brand, P.E. Cladis, P.L. Finn
}

\section{To cite this version:}

H.R. Brand, P.E. Cladis, P.L. Finn. The first bilayer ferroelectric liquid crystal. Journal de Physique Lettres, 1983, 44 (18), pp.771-776. 10.1051/jphyslet:019830044018077100 . jpa-00232261

\section{HAL Id: jpa-00232261 https://hal.science/jpa-00232261}

Submitted on 1 Jan 1983

HAL is a multi-disciplinary open access archive for the deposit and dissemination of scientific research documents, whether they are published or not. The documents may come from teaching and research institutions in France or abroad, or from public or private research centers.
L'archive ouverte pluridisciplinaire HAL, est destinée au dépôt et à la diffusion de documents scientifiques de niveau recherche, publiés ou non, émanant des établissements d'enseignement et de recherche français ou étrangers, des laboratoires publics ou privés. 
Classification

Physics Abstracts

$61.30-64.70 \mathrm{E}$

\title{
The first bilayer ferroelectric liquid crystal (*)
}

\author{
H. R. Brand \\ Institute for Theoretical Physics $\left({ }^{* *}\right)$, University of California, Santa Barbara, CA 93106, U.S.A. \\ P. E. Cladis and P. L. Finn \\ Bell Laboratories, Murray Hill, New Jersey 07974, U.S.A.
}

(Reçu le 24 mai 1983, accepté le 26 juillet 1983)

\begin{abstract}
Résumé. - Nous avons trouvé le premier smectic $\mathrm{C}$ chiral formé de paires de molécules fortement liées. Le directeur de la nouvelle phase, qui possède une polarisation permanente, peut être orienté dans un champ électrique comme une phase $\mathrm{C}$ chirale monocouche.

Abstract. - We have found the first chiral smectic C liquid crystal formed by strongly bound antiparallel pairs of molecules. The director of the new phase, which has a net permanent polarization, can be oriented in an electric field in a way similar to a chiral $\mathrm{C}$ phase formed by monomers.
\end{abstract}

In the field of liquid crystals, the layered phases in which there is at least a one dimensional density wave, called smectic phases, have attracted increasing attention over the last few years [1]. Of particular interest is the variety of smectic phases formed by dimers, i.e. pairs of partly overlapped molecules which are held together by dipolar interactions or charge transfer effects.

It turns out that in smectic A phases, i.e. phases in which the preferred orientation of the molecules is parallel to the layer normal, the layer spacing can be anywhere between one and two molecular lengths. Thus all incommensurate values $d / l$ between one and two with $d$ the layer spacing and $l$ the molecular length can be assumed. Various models have been put forward to account for these observations [2-4].

Whether dimers can also show tilted smectic phases like e.g. smectic $C$ (in addition to the layered structure of smectic A, the director $n$, characterizing the preferred direction of the molecules, is tilted at an angle with respect to the layer normal), has been addressed only very recently $[5-8]$.

In the present note, we discuss, for the first time, the effects of chirality on bilayer or partial bilayer smectic phases. This question is interesting from a fundamental point of view because the formation of dimerized or partially dimerized phases is always due to electric interactions of one type or another. As has been pointed out by Meyer [9] the occurrence of ferroelectricity in liquid crystals is implied by the helical structure of chiral smectics like $\mathrm{C}^{*}, \mathrm{~F}^{*}, \mathrm{I}^{*}$. On the other hand it has been pointed out very recently by two of the present authors [10] that it is also possible to

(*) Part of the work described here was done during a visit at Bell Laboratories.

(**) Supported by NSF Grant PHY 77-27084. 
have ferroelectric liquid crystals which are achiral. Therefore it seems to be an important question to find out to what extent the electric forces which are responsible for the existence of various types of dimerized phases are compatible with the existence of a helical structure and whether a permanent polarization can be associated with a chiral $\mathrm{C}$ phase composed of dimers.

To answer this question we investigated a mixture of $900 \mathrm{C}$ (4-n-nonyl-oxyphenyl 4'-cyano benzoate) [13] and $1200 \mathrm{C}$ (4-n-dodecyl-oxyphenyl 4'-cyanobenzoate)[13]. Mixtures of these two compounds are known to show stable, monotropic dimer $\mathbf{C}$ phases [7] with a temperature range which varied from 5 to $15^{\circ}$ (cf. ref. 7 for details) whereas the range of the $C$ phase in the pure compounds is very small. The stability of these dimer $\mathrm{C}$ phases derives from the strength of the lateral dipole of anti-parallel pairs of molecules. The longitudinal dipole moment of such monomer pairs cancel. The partially overlapped dimers have a (fully extended) length of $45 \AA$ in the stereo model (cf. Fig. 1).
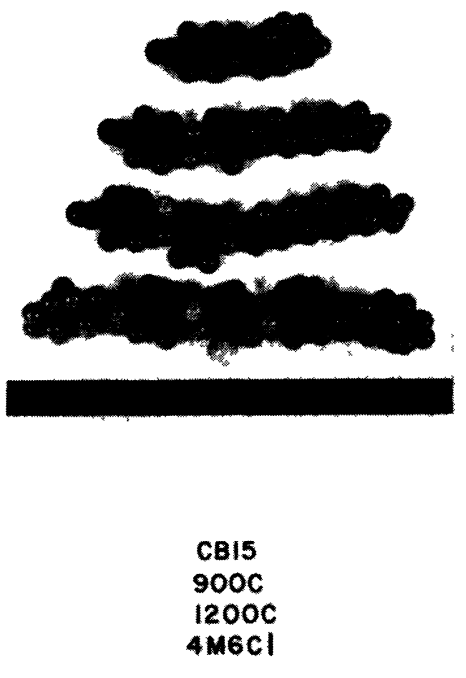
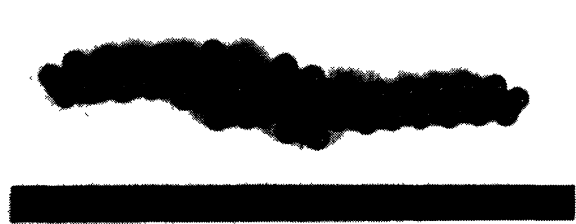

$900 \mathrm{C}-1200 \mathrm{C}$

DIMER.

Fig. 1. - Spacefilling models showing CB15 (19 $\AA), 4 \mathrm{M} 6 \mathrm{Cl}(37 \AA)$ and $900 \mathrm{C} / 1200 \mathrm{C}(45 \AA)$ pairs.

For our studies we started with a mixture of $47 \% 900 \mathrm{C}$ and $53 \% 1200 \mathrm{C}$ with the following sequence of transitions

$$
\text { Xtal } \quad \underset{45.6^{\circ} \mathrm{C}}{\leftarrow} \mathrm{C} \quad \underset{60.7^{\circ} \mathrm{C}}{\leftrightarrows} \mathrm{A} \underset{99.3^{\circ} \mathrm{C}}{\leftrightarrows} \text { Iso } \underset{\mathrm{mp} 59.7^{\circ} \mathrm{C}}{\leftrightarrows}
$$

In contrast to previous studies [7] the $C$ phase in the above mixture is enantiotropic. As chiralizing agent we used CB15 (4-cyano-4'-(2-methyl) butylbiphenyl), a cyano compound with two phenyl rings. The cyano end group gives rise to a strong longitudinal dipole similar to $900 \mathrm{C} / 1200 \mathrm{C}$ and thus favours dimer formation (see Fig. 1). For the phase sequence of CB15 one has

$$
\text { chol } \underset{-30^{\circ} \mathrm{C}}{\leftarrow} \text { Iso } \operatorname{mp~} 4^{\circ} \mathrm{C}
$$

In addition we used $4 \mathrm{M} 6 \mathrm{Cl}$ (2-chloro-phenyl-bis(p-n-4-methylhexyloxybenzoate)) (again see Fig. 1) as chiralizing material, a compound which has three phenyl rings and one chlorine atom off the side of the central phenyl ring giving rise to a transverse dipole. In contrast to CB15, 
$4 \mathrm{M} 6 \mathrm{Cl}$ is highly symmetric and does not have a dipole parallel to the long molecular axis. The phase sequence of $4 \mathrm{M} 6 \mathrm{Cl}$ is

$$
\text { Xtal } \underset{30^{\circ} \mathrm{C}}{\leftarrow} \mathrm{Ch} \underset{122.5^{\circ} \mathrm{C}}{\leftrightarrows} \text { Iso } \underset{\mathrm{mp} \mathrm{68}}{\stackrel{\circ}{\circ} \mathrm{C}}
$$

We prepared three mixtures $4 \% \mathrm{CB} 15$ in $900 \mathrm{C} / 1200 \mathrm{C}, 25 \% \mathrm{CB} 15$ in $900 \mathrm{C} / 1200 \mathrm{C}$ and $6.4 \% 4 \mathrm{M} 6 \mathrm{Cl}$ in $900 \mathrm{C} / 1200 \mathrm{C}$ and we have observed the following sequences of transitions :

a) $4 \% \mathrm{CB} 15$ in $900 \mathrm{C} / 1200 \mathrm{C}$

$$
\text { Xtal } \underset{42.1^{\circ} \mathrm{C}}{\leftarrow} \quad \mathrm{C}^{*} \underset{59^{\circ} \mathrm{C}}{\leftrightarrows} \quad \mathrm{A} \underset{98.6^{\circ} \mathrm{C}}{\leftrightarrows} \text { Iso } \underset{\mathrm{mp} 57.1^{\circ} \mathrm{C}}{\leftrightarrows}
$$

b) $25 \% \mathrm{CB} 15$ in $900 \mathrm{C} / 1200 \mathrm{C}$

$$
\text { Xtal } \underset{42.8^{\circ} \mathrm{C}}{\leftarrow} \mathrm{C}^{*} \underset{51^{\circ} \mathrm{C}}{\leftrightarrows} \quad \mathrm{A} \underset{94.3^{\circ} \mathrm{C}}{\leftrightarrows} \text { Iso } \underset{\mathrm{mp} 55.1^{\circ} \mathrm{C}}{\leftrightarrows}
$$

c) $6.4 \% 4 \mathrm{M} 6 \mathrm{Cl}$ in $900 \mathrm{C} / 1200 \mathrm{C}$

$$
\text { Xtal } \underset{62{ }^{\circ} \mathrm{C}}{\leftarrow} \mathrm{A} \underset{102.6^{\circ} \mathrm{C}}{\leftrightarrows} \text { Iso } \underset{\mathrm{mp} 74.9^{\circ} \mathrm{C}}{\leftrightarrows}
$$

The phase sequences listed were obtained from observations in the microscope, measurements of the layer spacing in $x$-ray and from differential scanning calorimetry.

Our x-ray data (Fig. $2 a, b$ ) for the CB15/900 C/1 $200 \mathrm{C}$ mixtures as well as for $900 \mathrm{C} / 1200 \mathrm{C}$ clearly show the behaviour typical for a smectic $\mathrm{A}$-smectic $\mathrm{C}$ transition, the layer spacing increases slowly in the A-phase as the temperature is lowered towards the A-C transition, peaks at the transition and then decreases rather sharply inside the $C^{*}$ phase (or C-phase respectively) with decreasing temperature indicating an increase in tilt angle. From the magnitude of the layer spacing at the $C$ to $A$ and $C^{*}$ to $A$ transitions we infer that the effect of increasing $C B 15$ concentration is to increase the degree of pairing in the mixture. From the DSC traces (Fig. 3) we see that the temperature range over which the $\mathrm{C}$-phase (or $\mathrm{C}^{*}$-phase) exists decreases as the CB15 concentration is enhanced and, presumably, the lateral dipole strength on average is reduced. It is interesting to note, how the magnitude and sharpness of the jump at the C-A and $\mathrm{C}^{*}$-A transition, indicating the second order nature of this transition, decrease as the concentration of CB15 increases. For the C-A transition, this jump is about $30 k_{\mathrm{B}}$ whereas for the $\mathrm{C}^{*}$-A transition shown, it is about $15 k_{\mathrm{B}}\left(k_{\mathrm{B}}\right.$ Boltzmann's constant).

This situation is completely different for the $4 \mathrm{M} 6 \mathrm{Cl} / 900 \mathrm{C} / 1200 \mathrm{C}$ mixture (Fig. $2 c$ ) where the principle effect of $4 \mathrm{M} 6 \mathrm{Cl}$ is to enhance the crystallization temperature both above its own and that of the $900 \mathrm{C} / 1200 \mathrm{C}$ mixture thus preempting the appearance of the smectic $\mathrm{C}^{*}$ phase. In figure $2 c$ the layer spacing increases monotonically until the sample crystallizes indicating the existence of only one liquid crystalline phase in this mixture, a smectic A phase. From the value of this layer spacing we infer that, at these concentrations, $4 \mathrm{M} 6 \mathrm{Cl}$ has not impeded dimer formation of $900 \mathrm{C} / 1200 \mathrm{C}$. In agreement with our microscopic observations and the results for the layer spacing the DSC curve for the $4 \mathrm{M} 6 \mathrm{Cl}$-mixture (Fig. 4) shows only two peaks.

To determine whether the dimerized $\mathrm{C}^{*}$ phases have a permanent polarization, we applied a dc electric field. Reversing the field resulted in a reorientation of the director giving rise to reasonably good contrast between the two states. When the field was turned off, the director orientation did not persist and the contrast decayed rapidly, a behaviour well familiar from the usual switching behaviour of a $C^{*}$ phase in thick cells [11] (cell thickness varied between 50 and $100 \mu \mathrm{m}$ ). For example, reversing the field in a square wave between $\pm 6 \times 10^{3} \mathrm{~V} / \mathrm{cm}$, the $4 \% \mathrm{CB} 15 \mathrm{mixture}$ 


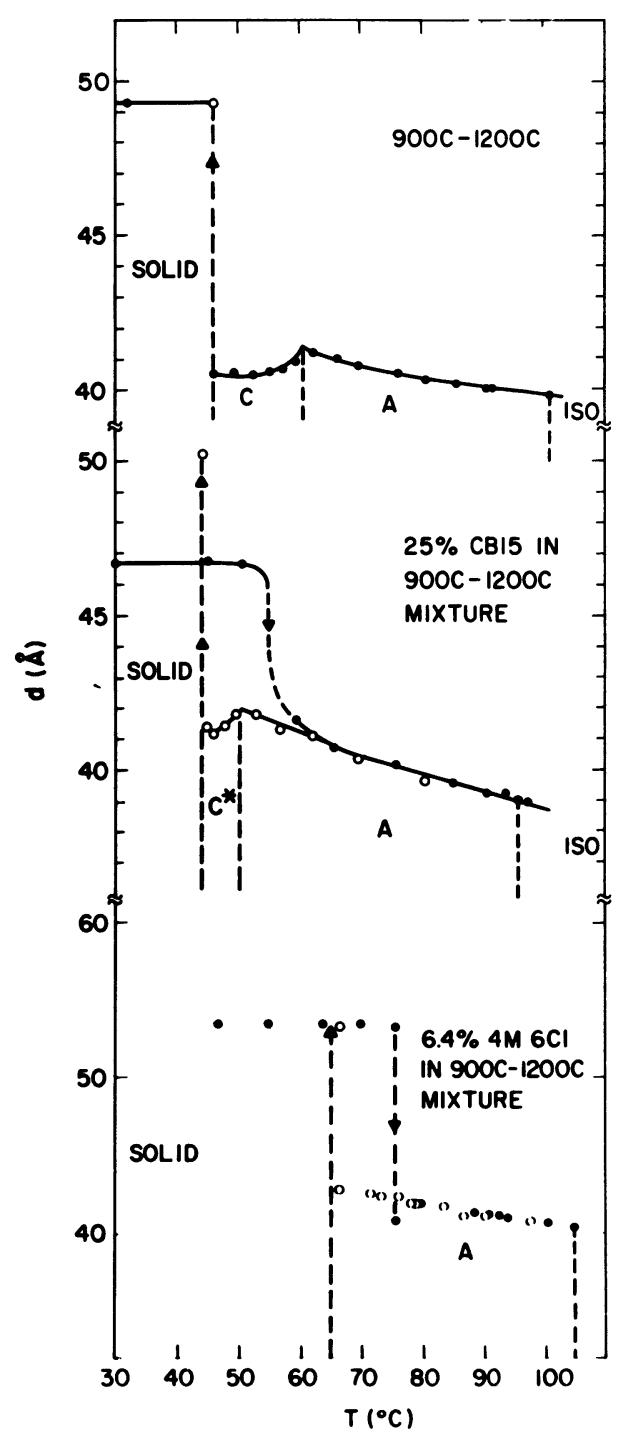

Fig. 2. - Layer spacing (d) versus temperature for the mixtures : a) $900 \mathrm{C} / 1200 \mathrm{C}, b) 25 \% \mathrm{CB} 15$ in $900 \mathrm{C} / 1200 \mathrm{C}$ and c) $6.4 \% 4 \mathrm{M} 6 \mathrm{Cl}$ in $900 \mathrm{C} / 1200 \mathrm{C}$. The filled circles were taken on heating, the open ones on cooling.

switched in $\sim 90 \mathrm{~ms}$ and the $25 \%$ mixture in $\sim 12 \mathrm{~ms}$. Electrohydrodynamic instabilities were observed in the $25 \%$ mixture but not in the $4.5 \%$ mixture at low voltages.

The results presented above might be understood qualitatively as follows. For the CB15/ $900 \mathrm{C} / 1200 \mathrm{C}$ mixtures a fraction of the $900 \mathrm{C} / 1200 \mathrm{C}$ dimers, which are very stable (high binding energy), is replaced by dimers containing a CB15 and a $900 \mathrm{C}$ or $1200 \mathrm{C}$ molecule respectively. These dimers from strongly overlapped pairs of a length of about $38 \AA$. A glance at de Gennes' " fish-eye " model [12] for the formation of chiral smectics reveals that, apart from a plane defined by the director and the layer normal, two ingredients are necessary for the formation of chiral smectic phases : a chiral group which gives a handedness to the molecule and a polarization perpendicular to the plane defined by the director and the layer normal which is also rigidly 


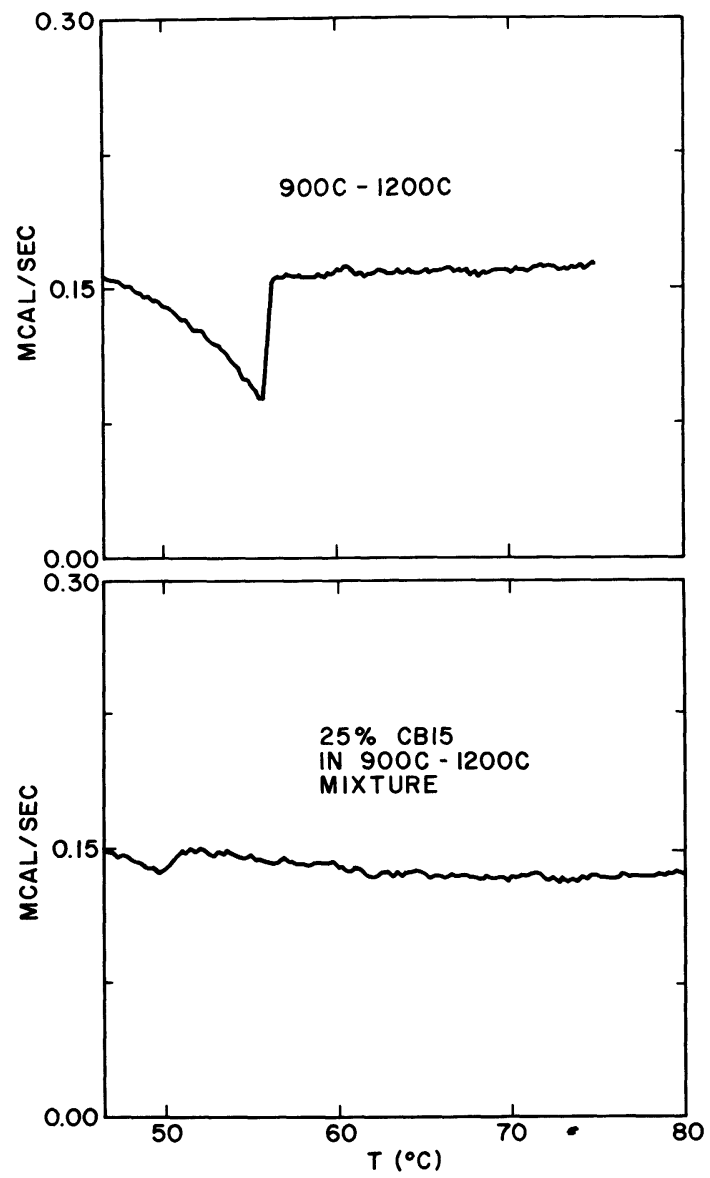

Fig. 3. - DSC of the $a$ ) A to $\mathrm{C}$ transition and $b$ ) A to $\mathrm{C}^{*}$ transition in the $900 \mathrm{C} / 1200 \mathrm{C}$ mixture (a) and the $25 \% \mathrm{CB} 15$ in $900 \mathrm{C} / 1200 \mathrm{C}$ mixture $(b)$. In $(a)$, a $7.14 \mathrm{mg}$ sample is used and in (b) $2.8 \mathrm{mg}$ of the CB15$900 \mathrm{C} / 1200 \mathrm{C}$ mixture is used. Cooling rate is $3 \% \mathrm{~min}$. in both cases. The specific heat jump for case $(a)$ is about $30 k_{\mathrm{B}}$ whereas in $(b)$ it is less than $15 k_{\mathrm{B}}\left(k_{\mathrm{B}}\right.$ Boltzmann's constant). In these mixtures, the effect of CB15 is to enhance pairing without appreciably affecting the solidification temperatures.

coupled to the chiral group. Two elements which emerge from this picture are i) the chiral group should be on the end of the molecule so that its effect is optimized and ii) the lateral polarization cannot freely rotate relative to the chiral group because that would lead to a zero effective polarization.

Attaching a strong transverse dipole to the asymmetric carbon itself could produce a chiral smectic with a large polarization. A striking example of this proposed mechanism is provided by HOBACPC (p-hexyloxybenzylidene-p'-amino 2-chloro- $\alpha$-propyl cinnamate) which has the highest polarization known for a pure compound showing chiral smectic phases.

If the polar group is separated from the asymmetric carbon, the polarization of the corresponding chiral smectic phases is typically [14] one order of magnitude smaller.

In summary, the strong lateral dipole of $4 \mathrm{M} 6 \mathrm{Cl}$ leads to a more dense packing of the $900 \mathrm{C} /$ $1200 \mathrm{C}$ dimers within a layer, so that crystallization takes place at higher temperatures than for « pure » $900 \mathrm{C} / 1200 \mathrm{C}$ and the CB15-(900 C/1 $200 \mathrm{C})$ mixtures. In the case of CB15-(900 C or $1200 \mathrm{C}$ ) dimers, the chiral function is provided by CB15 and the lateral dipole by the ester func- 


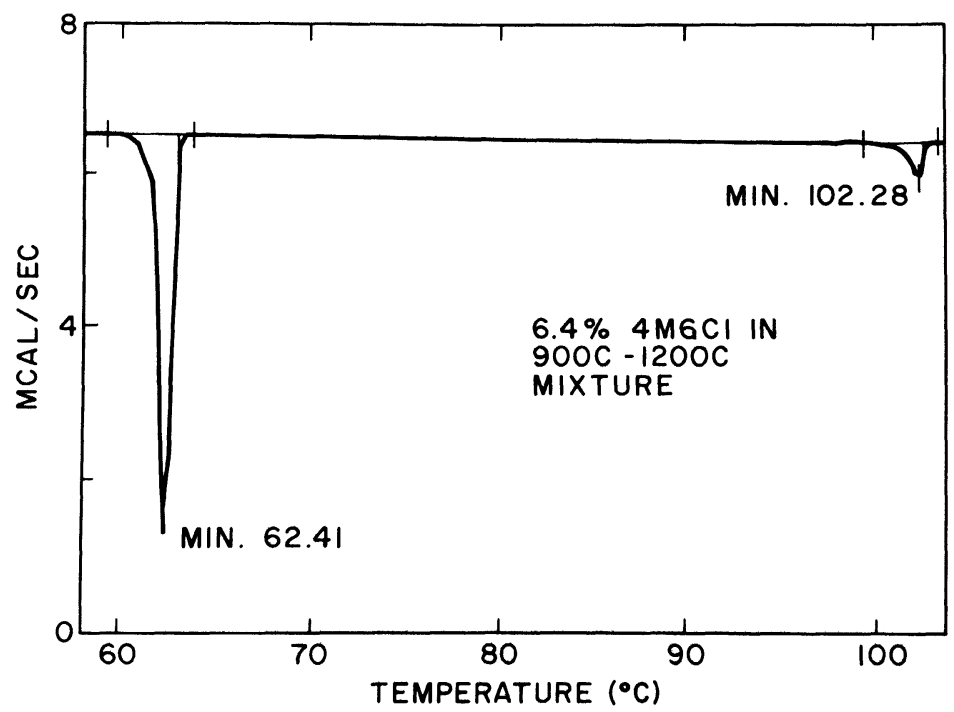

Fig. 4. - DSC cooling trace of the $4 \mathrm{M} 6 \mathrm{Cl}-900 \mathrm{C} / 1200 \mathrm{C}$ mixture. In this mixture, the effect of $4 \mathrm{M} 6 \mathrm{Cl}$ is to increase the crystallization and melting temperatures so that the $\mathrm{C}^{*}$ phase is never observed.

tion of $900 \mathrm{C}$ or $1200 \mathrm{C}$. Therefore, increasing the concentration of CB15 leads to an increase in the macroscopic polarization and hence a decrease in the switching times at low voltages. But it also leads to an increase in the local, longitudinal dipole of the molecule thus decreasing the stability of smectic $C^{*}$ and enhancing the tendency for the system to undergo electrohydrodynamic instabilities.

\section{References}

[1] Cf. e.g. Liquid Crystals of One- and Two-Dimensional Order, Helfrich, W. and Heppke, G. Eds. (Springer Series in Chemical Physics, Springer N.Y.) 1980, vol. 11.

[2] Cladis, P. E., Bogardus, R. K., Daniels, W. B. and Taylor, G. N., Phys. Rev. Lett. 39 (1977) 720.

[3] Cladis, P. E., Mol. Cryst. Liq. Cryst. 67 (1981) 177.

[4] Sigaud, G., Hardouin, F., Achard, M. F., Levelut, A. M., J. Physique 42 (1981) 107.

[5] Tinh, N. H., Hardouin, F., Destrade, C. and Levelut, A. M., J. Physique Lett. 43 (1982) L-133.

[6] Hardouin, F., Tinh, N. H. and Levelut, A. M., J. Physique Lett. 43 (1982) L-779.

[7] Cladis, P. E., FinN, P. L. and Goodby, J. W., to appear in Liquid Crystals and Ordered Fluids, A. C. Griffin and J. Johnson, Eds. (Plenum Press, Reading, Mass.) 1983.

[8] Göbl-WunsCh, A., HePPKe, G. and Hopf, R., Z. Naturforsch A 36 (1981) 213.

[9] Meyer, R. B., Mol. Cryst. Liq. Cryst. 40 (1977) 33.

[10] BRAND, H. R. and Cladis, P. E., submitted for publication.

[11] Cladis, P. E., Brand, H. R. and Finn, P. L., Phys. Rev. A, Rapid Communications, in print.

[12] DE Gennes, P. G., Physics of Liquid Crystals, second edition (Clarendon Press, Oxford) 1976.

[13] Goodby, J. W., Leslie, T. M., Cladis, P. E. and FinN, P. L., to appear in Liquid Crystals and Ordered Fluids, A. C. Griffin and J. Johnson Eds. (Plenum Press, Reading, Mass.) 1983.

[14] Martinot-Lagarde, P., Duke, R., Durand, G., Mol. Cryst. Liq. Cryst. 75 (1981) 249. 